\title{
Cardiac disease in diabetic end-stage renal disease
}

\author{
R.N. Foley ${ }^{1}$, B. F. Culleton ${ }^{1}$, P. S. Parfrey ${ }^{1}$, J. D. Harnett ${ }^{1}$, G. M. Kent ${ }^{1}$, D. C. Murray ${ }^{2}$, Paul E. Barre ${ }^{3}$ \\ ${ }^{1}$ The Division of Nephrology, the Health Sciences Centre, Memorial University, St. John's, Newfoundland, Canada \\ 2 The Division of Nephrology, Salvation Army Grace General Hospital, St. John's, Newfoundland, Canada \\ ${ }^{3}$ The Division of Nephrology, Royal Victoria Hospital, McGill University, Montreal, Quebec, Canada
}

Summary Little is known about the epidemiology of cardiac disease in diabetic end-stage renal disease. We therefore prospectively followed a cohort of 433 patients who survived 6 months after the inception of dialysis therapy for an average of 41 months. Clinical and echocardiographic data were collected yearly. At baseline, diabetic patients $(n=116)$ had more echocardiographic concentric left ventricular hypertrophy ( 50 vs $38 \%, p=0.04$ ), clinically diagnosed ischaemic heart disease $(32$ vs $18 \%, p=0.003)$ and cardiac failure (48 vs $24 \%, p<0.00001$ ) than nondiabetic patients $(n=317)$. After adjusting for age and sex, diabetic patients had similar rates of progression of echocardiographic disorders, and de novo cardiac failure, but higher rates of de novo clinically diagnosed ischaemic heart disease (RR 3.2, $p=0.0002)$, overall mortality ( $\mathrm{RR} 2.3, p<0.0001$ ) and cardiovascular mortality (RR 2.6, $p<0.0001$ ) than non-diabetic patients. Mortality was higher in diabetic patients following admission for clinically diagnosed ischaemic heart disease ( $R R$ 1.7, $p=0.05$ ) and cardiac failure (RR 2.2, $p=0.0003$ ). Among diabetic patients older age, left ventricular hypertrophy, smoking, clinically diagnosed ischaemic heart disease, cardiac failure and hypoalbuminaemia were independently associated with mortality. The excessive cardiac morbidity and mortality of diabetic patients seem to be mediated via ischaemic disease, rather than progression of cardiomyopathy while on dialysis therapy. Potentially remediable risk factors include smoking, left ventricular hypertrophy, and hypoalbuminaemia. [Diabetologia (1997) 40: 1307-1312]

Keywords Diabetic, end-stage renal disease, cardiac, morbidity, mortality.
Diabetes mellitus is the commonest cause of prevalent and incident end-stage renal disease (ESRD) in the western world $[1,2]$. Virtually every study of mortality in dialysis patients has shown that diabetic patients have a poorer survival than their non-diabetic ESRD counterparts. About half of this excess mortality can be attributed to cardiovascular causes [1]. It is already known that diabetes is an independent risk

Received: 25 March 1997 and in final revised form: 23 June 1997

Corresponding author: Dr. Foley, Memorial University of Newfoundland, The Health Sciences Centre, St. John's, Newfoundland, Canada, A1B 3 V6

Abbreviations: ESRD, End-stage renal disease; LV, left ventricular. factor for coronary artery disease $[3,4]$ and cardiac failure [5] in the non-uraemic population.

There is a dearth of information about the natural history and risk factors of cardiac disease in diabetic ESRD. The objectives of this study were to determine whether diabetic subjects differed from non-diabetic ESRD subjects with regard to: 1) prevalence of left ventricular echocardiographic disorders and of symptomatic cardiac disease at the start of dialysis therapy. 2) The rate of progression of echocardiographic parameters. 3) The incidence of symptomatic cardiac disease of new onset. 4) The lethality of cardiac events occurring while on dialysis therapy. 5) Mortality, after adjusting for imbalances in baseline comorbidity. 6) Finally, we wished to determine whether mortality risk factors, specific to diabetic patients with ESRD could be identified. 


\section{Patients and methods}

Patients. The design of this study has been described in detail elsewhere [6-15]. This prospective, inception cohort study started in 1982, and involved three university-affiliated, tertiary referral centres. Patients were eligible for entry to the study if (a) they survived for 6 months and (b) if they had a technically satisfactory echocardiogram within a year of starting renal replacement therapy. Patient recruitment finished in 1991. The mean patient follow-up was 41 months.

Data collection. At baseline, and at yearly intervals, a clinical assessment was undertaken to detect the presence of cardiovascular disease. At monthly intervals the data collected included blood pressure, haemoglobin and serum albumin levels and interdialytic weight gain in haemodialysis patients.

Baseline and annual echocardiography were performed using M-mode and 2-dimensional ultrasonography. Left ventricular mass (LV) index was calculated according to the Penn convention [16]. LV cavity volume was calculated by the formula of Pombo et al. [17]. The initial echocardiogram was performed (mean \pm SD) $3 \pm 4$ months (median 0 months) following the start of ESRD therapy. A repeat echocardiagram was performed on $92 \%$ of all patients still on dialysis at 1 year after starting dialysis therapy at a median interval of 13 months following the initial study.

\section{Definitions}

Non-insulin-treated diabetes mellitus: insulin-free interval more than 1 year.

Insulin-treated diabetes mellitus: absence of insulin-free interval more than 1 year.

Clinically diagnosed ischaemic heart disease: angina pectoris, myocardial infarction, coronary artery bypass surgery or percutaneous transluminal angioplasty.

Cardiac failure: dyspnoea plus two of the following - raised jugular venous pressure, bibasalar crackles, pulmonary venous hypertension or interstitial oedema on chest X-ray, requiring hospitalization or extra ultrafiltration.

Echocardiographic classification: subjects were divided into four mutually exclusive categories:

Systolic dysfunction: fractional shortening $25 \%$ or less.

$L V$ dilatation: $\mathrm{LV}$ cavity volume over $90 \mathrm{ml} / \mathrm{m}^{2}$, fractional shortening over $25 \%[8,17]$.

Concentric LV hypertrophy: LV mass index over $100 \mathrm{~g} / \mathrm{m}^{2}$ in females, over $131 \mathrm{~g} / \mathrm{m}^{2}$ in males, LV cavity volume $90 \mathrm{ml} / \mathrm{m}^{2}$, or less, fractional shortening over $25 \%$ [8, 17-19].

Normal LV: LV mass index $100 \mathrm{~g} / \mathrm{m}^{2}$ or less in females, $131 \mathrm{~g} /$ $\mathrm{m}^{2}$ or less in males, LV cavity volume $90 \mathrm{ml} / \mathrm{m}^{2}$ or less, fractional shortening over $25 \%$.

Mode of dialysis: one in use at 3 months following inception of dialysis.

Cardiovascular mortality: death due to myocardial infarction, sudden death, other cardiac cause or other non-cardiac vascular cause such as stroke or peripheral vascular disease.

Statistical analysis. Insulin-treated and non-insulin-treated patients were considered as a single group for comparison with non-diabetic patients. Although we compared the baseline characteristics and outcomes of insulin-treated and non-insulin-treated diabetic patients, we considered these comparisons as subsidiary, because we did not use accurate methods to determine whether patients truly had insulin-dependent or noninsulin-dependent diabetes mellitus. The echocardiographic outcomes studied were the changes in LV mass index, cavity volume index and fractional shortening between the baseline and first follow-up echocardiogram. The clinical outcomes studied were: rates of new-onset ischaemic heart disease, new-onset cardiac failure, overall mortality, cardiovascular mortality, non-cardiovascular mortality, mortality before and after 2 years, mortality after first admission for ischaemic heart disease while on dialysis therapy and mortality after first admission for cardiac failure while on dialysis therapy. Patients were censored on transplantation or final follow-up for the analysis of clinical events. We examined the association between baseline risk factors and overall mortality in analyses that included only diabetic patients. All statistical tests are two-tailed with a $p$-value less than 0.05 taken to indicate statistical significance. The proportional hazard model was used to adjust the diabetic-to-non-diabetic hazard ratios of clinical outcomes for baseline age, gender and co-morbidity. Echocardiographic outcomes were similarly adjusted, using analysis of variance with covariate adjustment.

\section{Results}

Patient characteristics at inception of dialysis therapy. Compared to non-diabetic patients, diabetic patients were less likely to have hypertension for more than 10 years, more likely to use peritoneal dialysis than haemodialysis and had lower serum albumin levels (Table 1). Diabetic patients were more likely to have concentric LV hypertrophy on baseline echocardiography, and were likely to have had clinically diagnosed ischaemic heart disease, previous myocardial infarction and cardiac failure prior to inception of dialysis therapy (Table 1).

Outcomes. When adjustment was made for baseline age and sex, diabetic and non-diabetic patients had a similar tendency towards progressive LV hypertrophy, dilatation and systolic dyfunction on serial echocardiography (data not shown).

Diabetic patients were more likely to develop clinically diagnosed ischaemic heart disease of new onset. Rates of new onset cardiac failure were similar in diabetic and non-diabetic patients. Each of the following were more likely in diabetic patients: overall mortality, cardiovascular mortality, non-cardiovascular mortality, mortality before and after 2 years, mortality after an episode of clinically diagnosed ischaemic heart disease and mortality after an episode of cardiac failure (Table 2). The excess mortality of diabetic patients could not be explained by differences in measurable co-morbidity at inception of dialysis therapy: when adjustment was made for age, sex, duration of hypertension, smoking, serum cholesterol, LV mass index, cavity volume, fractional shortening, ischaemic heart disease, cardiac failure, initial mode of dialysis therapy, baseline haemoglobin, mean arterial blood pressure and serum albumin levels, the relative hazard rate was 2.2 (95\% confidence interval 1.5-3.2, $p=0.0001)$ for diabetic compared to non-diabetic subjects. 
Table 1. Comparison of baseline characteristics of diabetic and non-diabetic patients

\begin{tabular}{|c|c|c|c|}
\hline & $\begin{array}{l}\text { Diabetic } \\
(n=116)\end{array}$ & $\begin{array}{l}\text { Non-diabetic } \\
(n=317)\end{array}$ & $P$ value \\
\hline Age (years) & $53 \pm 15$ & $50 \pm 17$ & 0.2 \\
\hline Female sex & $35 \%$ & $36 \%$ & 0.8 \\
\hline Diabetic nephropathy & $74 \%$ & $0 \%$ & \\
\hline Hypertension $>10$ years & $17 \%$ & $29 \%$ & 0.01 \\
\hline Serum cholesterol $(\mathrm{mmol} / \mathrm{l})$ & $5.5 \pm 1.6$ & $5.2 \pm 1.6$ & 0.1 \\
\hline $\begin{array}{l}\text { Serum cholesterol } \\
>6.0 \mathrm{mmol} / \mathrm{l}\end{array}$ & $31 \%$ & $23 \%$ & 0.09 \\
\hline Current smoker & $30 \%$ & $37 \%$ & 0.2 \\
\hline Haemoglobin $(\mathrm{g} / \mathrm{l})$ & $86 \pm 18$ & $83 \pm 17$ & 0.1 \\
\hline Mean arterial $\mathrm{BP}(\mathrm{mm} \mathrm{Hg})$ & $106 \pm 15$ & $105 \pm 16$ & 0.6 \\
\hline Serum albumin $(g / l)$ & $33 \pm 5$ & $35 \pm 6$ & 0.0002 \\
\hline LV mass index $\left(\mathrm{g} / \mathrm{m}^{2}\right)$ & $164 \pm 41$ & $157 \pm 51$ & 0.2 \\
\hline $\mathrm{LV}$ cavity volume $\left(\mathrm{ml} / \mathrm{m}^{2}\right)$ & $80 \pm 30$ & $86 \pm 40$ & 0.1 \\
\hline$\%$ fractional shortening & $32 \pm 8$ & $34 \pm 8$ & 0.07 \\
\hline \multicolumn{4}{|c|}{$\begin{array}{l}\text { Echocardiographic classification: } \\
\text { Normal LV }\end{array}$} \\
\hline (reference category) & $11 \%$ & $17 \%$ & - \\
\hline Concentric LV hypertrophy & $50 \%$ & $38 \%$ & 0.04 \\
\hline LV dilatation & $21 \%$ & $31 \%$ & 0.8 \\
\hline Systolic dysfunction & $18 \%$ & $15 \%$ & 0.1 \\
\hline \multicolumn{4}{|l|}{ Clinically diagnosed } \\
\hline Angina pectoris & $23 \%$ & $16 \%$ & 0.08 \\
\hline Myocardial infarction & $21 \%$ & $9 \%$ & 0.001 \\
\hline Cardiac failure & $48 \%$ & $24 \%$ & $<0.00001$ \\
\hline
\end{tabular}

Insulin-treated $(n=65)$ and non-insulin-treated $(n=51)$ patients were significantly different $(p<0.05)$ from each other for the variables age ( $48 \pm 14$ vs $59 \pm 12$ years, respectively), diabetic nephropathy ( 92 vs $51 \%$ respectively), hypertension $>10$ years ( 11 vs $26 \%$, respectively) and use of peritoneal dialysis (65 vs $41 \%$, respectively)

Figure 1 shows graphically that the probability of developing clinically diagnosed ischaemic heart disease of new onset was much higher in diabetic than non-diabetic subjects. Figure 2 shows a much lower overall survival in diabetic subjects, with median survival times of 32.4 months, compared with 57.5 months in non-diabetic subjects.

Mortality risk factors in diabetic subjects. Among diabetic subjects, older age and cardiac failure at baseline were associated with mortality in all time frames (Table 3). Clinically diagnosed ischaemic heart disease and cardiac failure were associated with mortality before 2 years. Older age, smoking, high LV mass index and hypoalbuminaemia were associated with mortality after 2 years (Table 3 ).

\section{Discussion}

There is very little published literature about cardiovascular disease in diabetic ESRD. It would be tempting to assume that the cardiac disease of diabetic ESRD patients relates to factors in their predialysis life about which little can be done when they actually
Table 2. Outcomes of diabetic patients relative to non-diabetic patients

\begin{tabular}{|c|c|c|c|}
\hline & $\begin{array}{l}\text { Diabetic } \\
(n=116)\end{array}$ & $\begin{array}{l}\text { Non- } \\
\text { diabetic } \\
(n=317)\end{array}$ & $\begin{array}{l}\text { Adjusted } \\
\text { Hazard } \\
\text { Ratio }^{\mathrm{a}}\end{array}$ \\
\hline $\begin{array}{l}\text { De novo clinically } \\
\text { diagnosed ischaemic } \\
\text { heart disease }\end{array}$ & $24 \%(19 / 79)$ & $\begin{array}{l}8 \%(21 / 259) \\
p=0.0001\end{array}$ & $\begin{array}{l}3.2(1.7-1.6) \\
p=0.0002\end{array}$ \\
\hline $\begin{array}{l}\text { De novo cardiac } \\
\text { failure }\end{array}$ & $27 \%(16 / 60)$ & $\begin{array}{l}23 \%(55 / 240) \\
p=0.6\end{array}$ & $\begin{array}{l}1.3(0.7-2.3) \\
p=0.4\end{array}$ \\
\hline $\begin{array}{l}\text { Death: } \\
\text { Overall }\end{array}$ & $53 \%$ & $\begin{array}{l}28 \% \\
p<0.00001\end{array}$ & $\begin{array}{l}2.3(1.7-3.2) \\
p<0.00001\end{array}$ \\
\hline Cardiovascular & $31 \%$ & $\begin{array}{l}14 \% \\
p=0.00007\end{array}$ & $\begin{array}{l}2.6(1.7-4.0) \\
p<0.0001\end{array}$ \\
\hline Non-cardiovascular & $22 \%$ & $\begin{array}{l}14 \% \\
p=0.03\end{array}$ & $\begin{array}{l}2.0(1.2-3.3) \\
p=0.006\end{array}$ \\
\hline Within 2 years & $28 \%$ & $\begin{array}{l}13 \% \\
p=0.0002\end{array}$ & $\begin{array}{l}2.3(1.5-3.7) \\
p=0.0003\end{array}$ \\
\hline After 2 years & $68 \%(30 / 44)$ & $33 \%(48 / 147)$ & $\begin{array}{l}2.3(1.4-3.6) \\
p=0.0006\end{array}$ \\
\hline $\begin{array}{l}\text { Following clinically } \\
\text { diagnosed ischaemic } \\
\text { heart disease occur- } \\
\text { ring after starting } \\
\text { dialysis therapy }\end{array}$ & $83 \%(29 / 35)$ & $\begin{array}{l}59 \%(30 / 51) \\
p=0.02\end{array}$ & $\begin{array}{l}1.7(1.0-2.9) \\
p=0.05\end{array}$ \\
\hline $\begin{array}{l}\text { Following cardiac } \\
\text { failure occurring } \\
\text { after starting } \\
\text { dialysis therapy }\end{array}$ & $85 \%(17 / 20)$ & $\begin{array}{l}55 \%(52 / 95) \\
p=0.0003\end{array}$ & $\begin{array}{l}2.2(1.4-3.3) \\
p=0.0003\end{array}$ \\
\hline
\end{tabular}

${ }^{a}$ Adjusted, using proportional hazards regression, for age and sex at baseline. Overall mortality was higher $(64 \%)$ in non-insulin-treated than insulin-treated patients $(45 \%, p=0.03)$

reach ESRD. Whether such an assumption is justified is, unfortunately, an open question. A highly noteworthy randomized trial randomly assigned insulin-dependent diabetic patients with ERSD who had significant coronary artery stenosis, but normal ejection fraction and absence of typical anginal pain, to medical or surgical management: in 8.4 months of follow-up $15 \%$ of the surgical group had a cardiovascular endpoint, compared with $77 \%$ in the medically managed group [20]. These types of data suggest that much could be done to prevent or treat cardiac disease in diabetic ESRD. The clinical epidemiology of cardiac disease in diabetic ESRD needs to be given a high priority in order for appropriate interventions to be targeted.

The main findings of this study were: 1) Diabetic patients were more likely to have concentric LV hypertrophy and much more likely to have had ischaemic heart disease and cardiac failure at baseline than non-diabetic subjects. 2) Diabetic patients were much more likely than non-diabetic patients to have had a previous myocardial infarct, but were equally likely to have symtomatic angina pectoris, suggesting the possibility that coronary disease is more likely to be silent in diabetic than non-diabetic subjects. 3) The rate of progression of echocardiographic 


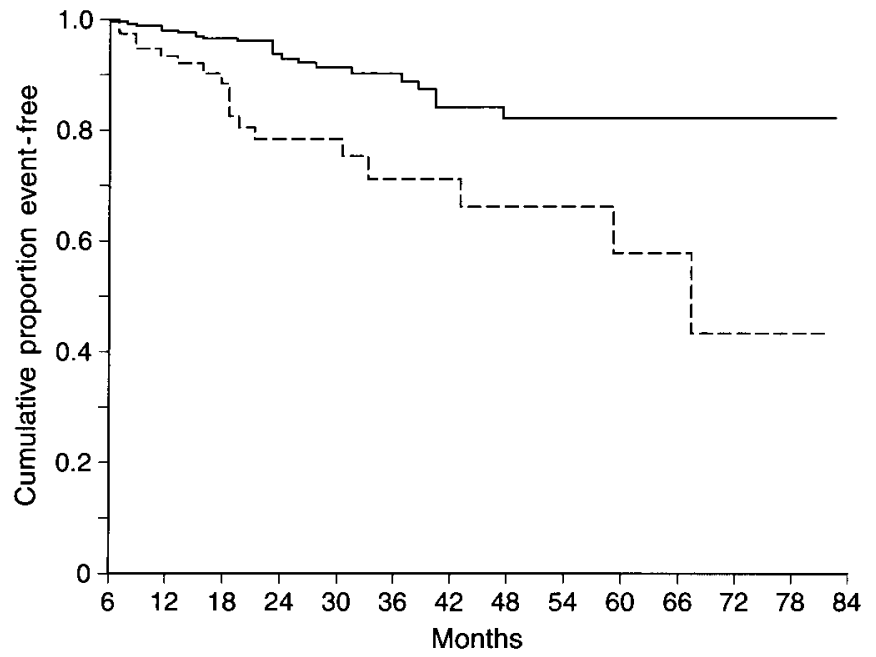

Fig. 1. Kaplan-Meier curves showing the time to first episode of new-onset ischaemic heart disease in diabetic (--.--) and non-diabetic subjects (- $)$. $p=0.0001$ by the log-rank test

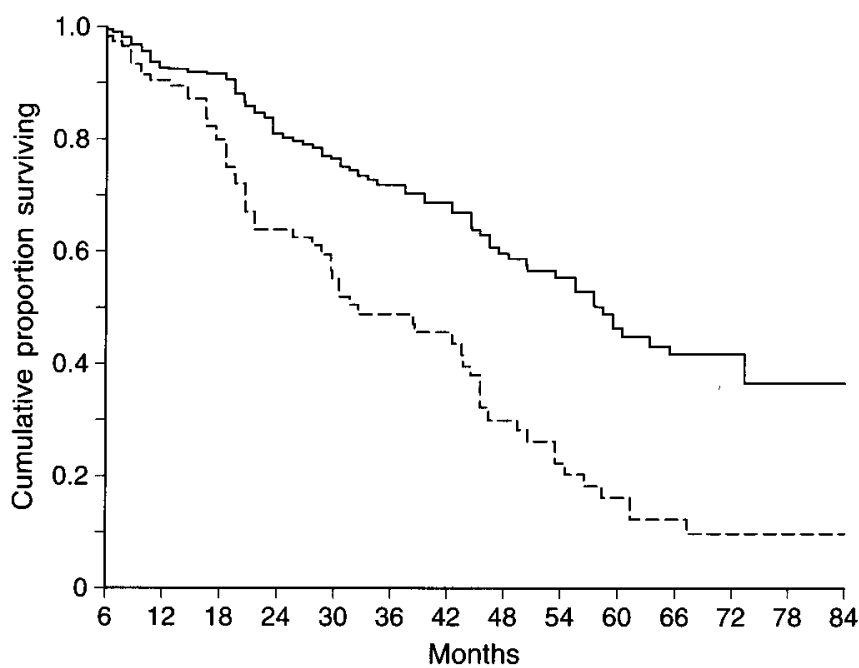

Fig. 2. Kaplan-Meier curves showing the survival of diabetic (--.-) and non-diabetic subjects (-). $p<0.0001$ by the log-rank test

disorders was very similar in diabetic and non-diabetic patients. 4) Diabetic patients with no previous history of ischaemic heart disease were much more likely to develop de novo ischaemic heart disease than their non-diabetic counterparts. On the contrary, diabetic and non-diabetic patients were equally likely to develop de novo cardiac failure. 5) The development of clinical events (cardiac failure and ischaemic heart disease to a lesser extent) was associated with a much poorer subsequent survival in diabetic than non-diabetic subjects. 6) The higher mortality of diabetic patients was not adequately explained by differences in demographic, clinical or echocardiographic parameters at the inception of dialysis therapy. 7) The mortality risk factors for diabetic patients were older age, smoking, clinically diagnosed ischaemic heart disease, cardiac failure, high LV mass index and low
Table 3. Summary of baseline factors associated with mortality in diabetic patients

\begin{tabular}{lll}
\hline & $\begin{array}{l}\text { Adjusted } \\
\text { hazard ratio } \\
\text { (95\% Confidence }\end{array}$ & \\
& Interval) & \\
& & \\
\hline $\begin{array}{l}\text { Mortality in all time frames } \\
\text { Age (per decade) }\end{array}$ & $1.2(1.0-1.5)$ & 0.05 \\
Cardiac failure & $2.3(1.5-4.0)$ & 0.002 \\
$\begin{array}{l}\text { Mortality before 2 years } \\
\text { Clinically diagnosed ischaemic }\end{array}$ & \\
$\begin{array}{l}\text { heart disease } \\
\text { Cardiac failure }\end{array}$ & $2.1(1.0-4.4)$ & 0.04 \\
$\begin{array}{l}\text { Mortality after 2 years } \\
\text { Age (per decade) }\end{array}$ & $3.2(1.4-7.5)$ & 0.006 \\
$\begin{array}{l}\text { Current smoker } \\
\text { LV mass index (per } 20 \mathrm{~g} / \mathrm{m}^{2} \text { rise) }\end{array}$ & $1.3(1.0-1.9)$ & 0.05 \\
Serum albumin (per $10 \mathrm{~g} / \mathrm{l}$ fall) & $2.7(1.3-5.6)$ & 0.05 \\
\hline
\end{tabular}

${ }^{a}$ Adjusted, using proportional hazards regression, for age and sex at baseline. The baseline variables tested for association with mortality outcomes were: age, sex, hypertension over 10 years, current smoking, serum cholesterol, clinically diagnosed ischaemic heart disease, cardiac failure, LV mass index, LV cavity volume, LV fractional shortening, haemoglobin level, mean arterial blood pressure level, serum albumin level and mode of dialysis therapy (haemodialysis or peritoneal dialysis)

serum albumin levels. At least some of these risk factors are potentially remediable.

There is a considerable literature suggesting the existence of a specific diabetic cardiomyopathy [2127]. The largest echocardiographic study comes from the Framingham Study, which examined diabetic patients without symptomatic cardiac disease. Female diabetic patients were found to have larger wall thickness, relative wall-thickness, end-diastolic diameter and relative wall thickness than non-diabetic patients. Male diabetic patients had slightly lower fractional shortening [27]. In our study, diabetic patients had a higher baseline prevalence of concentric LV hypertrophy than non-diabetic patients. The burden of clinically manifest cardiac disease in diabetic patients starting ESRD treatment was staggering. One third had a history of ischaemic heart disease, and half had experienced an episode of cardiac failure. It is worth reiterating that survival for 6 months was an inclusion criterion for this study and that the proportion of diabetic subjects with silent coronary artery disease is likely to be even higher than reported here. As such this study probably underestimates the burden of cardiac disease in diabetic ESRD.

Diabetic patients, initially free of ischaemic heart disease at the start of dialysis, were much more likely to develop ischaemic heart disease than equivalent non-diabetic patients. It is well-established that diabetes is an independent risk factor for coronary artery disease in the general population [3, 4]. Diabetic and non-diabetic patients were equally likely to develop cardiac failure for the first time, a common 
occurrence in this cohort of patients. The survival of diabetic dialysis patients was very poor after the occurrence of clinically defined cardiac events, such as ischaemic heart disease and cardiac failure.

The mortality of diabetic patients greatly exceeded that of non-diabetic patients. This excess mortality could not be adequately explained by imbalances in age or co-morbidity at baseline. Clinically defined ischaemic heart disease predicted mortality up to 2 years but was not associated with later mortality. Weinrauch et al. [28] have reported a lack of association between ischaemic heart disease and mortality in diabetic ESRD. The correlation between symtoms of ischaemic heart disease and coronary arterial narrowing is poor in ESRD patients with diabetes [29]. The presence of cardiac failure at inception of dialysis was a strong predictor of death in diabetic patients in this study. Smoking, LV mass index and hypoalbuminaemia were associated with mortality after a lag phase of about 2 years. A number of other authors have reported that smoking is particularly harmful in diabetic patients with advanced renal impairment $[30,31]$. Smoking is a major cardiovascular risk factor in non-uraemic diabetic patients. A meta-analysis of several cardiovascular risk reduction trials showed that stopping smoking was the intervention with the biggest impact on survival in diabetic patients [32]. Weinrauch et al. [28] reported that echocardiographic abnormalities (abnormal LV wall motion and/or LV dilatation) were better predictors of outcome than a prior history of angina pectoris, myocradial infarction, or congestive heart failure. On the other hand, there was no association between LV hypertrophy and myocardial infarction or sudden death in the large, prospective, German multicentre study reported by Koch et al. [33, 34]. It has been speculated that malnutrition is responsible for much of the excess mortality of diabetic patients with ESRD [35]. The strong association between hypoalbuminaemia and mortality seen in this study lends support to this viewpoint. We observed no independent association between serum cholesterol levels and mortality in this study. On the other hand, diabetic patients dying from myocardial infarction had higher total cholesterol, LDL cholesterol, LDL/HDL ratio and apolipoprotein B levels than survivors in the German study alluded to above $[33,34]$. Other factors suggested as cardiovascular risk factors in diabetic ESRD include poor glycaemic control [31], lower dialysis intensity [36] and accumulation of advanced glycosylation end-products [37]. It is a matter of debate whether peritoneal dialysis or haemodialysis is associated with longer survival time in diabetic ESRD [38-42].

Several potential limitations of this study need to be mentioned. Firstly, the classfication of diabetic patients into insulin-treated and non-insulin treated based merely on the presence or absence of an insulin-free interval of 1 year is arbitrary. Inception of dialysis therapy was the starting point for this study. Diagnostic separation into IDDM vs NIDDM would have occurred much earlier. Such categorisation would not usually have been performed by the physicians caring for the patients at the time dialysis was started. Similar reservations can be made about the cause of ESRD, particularly whether diabetic nephropathy was present or not. It would be preferable to delineate the actual coronary anatomy rather than to rely on symptoms of ischaemic heart disease. This would, however, be difficult to do in an epidemiological study. Cardiac failure is a clinical definition; because most ESRD patients have a limited capacity to excrete salt and water, one is never entirely certain whether the heart has failed the body or vice versa. Be that as it may, admission for pulmonary oedema (whether due primarily to fluid overload, pump failure, or both) identified a group with an appalling prognosis, with two thirds of all deaths prefaced by such an event $[7,13]$. This study was designed and implemented nearly 15 years ago. The lipid parameters collected would be viewed as unsophisticated and incomplete by todays standards. We did not include indices of dialysis adequacy, or indices of glycaemic control as part of the study protocol, again reflecting practices typical of the early 1980 s. Despite its limitations, this study has the advantages of a prospective design, a uniform inception point and very long follow-up. It shows that cardiac events occur at an alarming rate in diabetic patients. The study points to several risk factors for death in diabetic patients. Many of these risk factors are potentially reversible. Well designed intervention studies are greatly needed to alleviate the burden of cardiac disease in diabetic ESRD.

Acknowledgements. This research was funded in its initial stage by the Canadian Heart Foundation, and subsequently by the Kidney Foundation of Canada and by the Amgen Corporation, Thousand Oaks, California, USA

\section{References}

1. Perneger TV, Brancati FL, Whelton PK, Klag MJ (1994) End-stage renal disease attributable to diabetes mellitus. Ann Intern Med 121: 912-918

2. United States Renal Data System. USRDS (1995) Annual Report. US Department of Health and Human Services, National Institute of Diabetes and Digestive and Kidney Diseases, Bethesda, MD

3. Kannel WB, McGee DL (1979) Diabetes and cardiovascular disease: the Framingham Study. JAMA 241: 2035-2038

4. Valsania P, Zarich SW, Kowalhuk GJ, Kosinski E, Warram JH, Krowelski AS (1991) Severity of coronary artery disease in young patients with insulin-dependent diabetes mellitus. Am Heart J 122: 695-700

5. Kannel WB, Hjortland MC, Castelli WP (1974) Role of diabetes in congestive heart failure: the Framingham Study. Am J Cardiol 34: 29-34

6. Foley RN, Parfrey PS, Harnett JD, et al. (1995) Clinical and echocardiographic disease in patients starting end-stage renal disease therapy. Kidney Int 47: 186-192 
7. Harnett JD, Foley RN, Kent GM, Barre PN, Murray D (1995) Congestive heart failure in dialysis patients: prevalence, incidence, prognosis and risk factors. Kidney Int 47: 884-890

8. Foley RN, Parfrey PS, Harnett JD, Kent GM, Murray DC, Barre PE (1995) The prognostic importance of left ventricular geometry in uremic cardiomyopathy. $\mathrm{J}$ Am Soc Nephrol 5: 2024-2031

9. Parfrey PS, Harnett JD, Foley RN, et al. (1995) Impact of renal transplantation on uremic cardiomyopathy. Transplantation 15: 908-914

10. Foley RN, Parfrey PS, Harnett JD, et al. (1996) Hypocalcemia, morbidity and mortality in end-stage renal disease. Am J Nephrol 16: 386-393

11. Foley RN, Parfrey PS, Harnett JD, Kent GM, Murray DC, Barre PE (1996) The impact of anemia on cardiomyopathy, morbidity and mortality in end-stage renal disease. Am J Kidney Dis 28: 53-61

12. Foley RN, Parfrey PS, Harnett JD, Kent GM, Murray DC, Barre PE (1996) Hypoalbuminemia, cardiac morbidity and mortality in end-stage renal disease. J Am Soc Nephrol 7: 728-736

13. Foley RN, Parfrey PS, Harnett JD, Kent GM, Murray DC, Barre PE (1996) The impact of hypertension on cardiomyopathy, morbidity and mortality in end-stage renal disease. Kidney Int 49: 1379-1385

14. Parfrey PS, Foley RN, Harnett JD, Kent GM, Murray DC, Barre PE (1996) Outcome and risk factors for left ventricular disorders in chronic uraemia. Nephrol Dial Transplant 11: $1277-1285$

15. Parfrey PS, Foley RN, Harnett JD, Kent GM, Murray DC, Barre PE (1996) Outcome and risk factors of ischemic heart disease in chronic uremia. Kidney Int 49: 1428-1434

16. Devereux RB, Alonso DR, Lutas EM, et al. (1986) Echocardiographic assessment of left ventricular hypertrophy: comparison to necropsy findings. Am J Cardiol 57:450-458

17. Pombo JF, Troy BL, Russell RO Jr (1971) Left ventricular volumes and ejection fractions by echocardiography. Circulation 43: $480-490$

18. Levy D, Savage DD, Garrison RJ, et al. (1987) Echocardiographic criteria for left ventricular hypertrophy: the Framingham Study. Am J Cardiol 59: 956-960

19. Huwez FU, Pringle SD, Macfarlane PW (1992) A new classification of left ventricular geometry based on M-mode echocardiography. Am J Cardiol 70: 681-688

20. Manske CL, Wang Y, Rector T, Wilson RF, White CW (1992) Coronary revascularization in insulin-dependent diabetic patients with chronic renal failure. Lancet 340: 9981002

21. Schultz R (1876) Advanced cardiac insufficiency, a frequent complication of diabetes mellitus, requiring attention. Berl Klinische Wochen Schrift 6: 4-5

22. Blumental HT, Alex M, Goldenberg S (1960) A study of lesions of the intramural coronary by branches in diabetes mellitus. Arch Pathol 70: 27-42

23. Zoneraich S, Silverman G (1978) Myocardial small vessel disease in diabetic patients. In: Zoneraich $S$ (ed) Diabetes and the Heart, Charles C Thomas, Springfield pp 3-18

24. Shapiro LM, Howatt AP, Calter MM (1981) Left ventricular function in diabetes mellitus I. Methodology and prevalence and spectrum of abnormalities. Br Heart J 45 122-128

25. Shapiro LM, Leatherdale BA, MacKinnon J, et al. (1981) Left ventricular function in diabetes mellitus II. Relation between clinical features and left ventricular function. $\mathrm{Br}$ Heart J 45: 129-132

26. Theusen L, Christiansen JS, Mogensen CE, et al. (1988) Echocardiographic-determined left ventricular wall characteristics in insulin dependent diabetic patients. Acta Med Scand 224: 343-348

27. Galderisi M, Anderson KM, Wilson PWF, et al. (1991) Echocardiographic evidence for a distinct diabetic cardiomyopathy (The Framingham Heart Study) Am J Cardiol 68: 85-89

28. Weinrauch LA, D'Elia JA, Gleason RE, et al. (1992) Usefulness of left ventricular size and function in predicting survival in chronic dialysis patients with diabetes mellitus. Am J Cardiol 70: 300-303

29. Manske CL, Thomas W, Wang Y, Wilson RF (1992) Screening diabetic transplant candidates for coronary artery disease: identification of a low-risk subgroup. Kidney Int 44: $617-621$

30. McMillan MA, Briggs JD, Junor BS (1990) Outcome of renal replacement therapy in patients with diabetes mellitus. BMJ 301: 540-544

31. Manske CL, Wilson RF, Wang Y, Thomas W (1992) Prevalence of and risk factors for angiographically determined coronary artery disease in type-1 diabetic patients with nephropathy. Arch Intern Med 152: 2450-2455

32. Yudkin JS (1993) How can we best prolong life? Benefits of coronary risk factor reduction in non-diabetic and diabetic subjects. BMJ 306: 1313-1318

33. Koch M, Thomas B, Tschope W, Ritz E (1993) Survival and predictors of death in dialysed diabetic patients. Diabetologia 36: 1113-1117

34. Tschope W, Koch M, Thomas B, Ritz E (1994) Serum lipids predict cardiac death in diabetic patients on maintenance haemodialysis. Results of a prospective study. The German Study Group Diabetes and Uremia. Nephron 64: 354-358

35. Lowrie EG, Lew NL, Huang WH (1992) Race and diabetes as death predictors in haemodialysis patients. Kidney Int Suppl 38:S22-S31

36. Collins AJ (1993) How can the mortality rate of chronic dialysis patients be reduced? Semin Dial 6: 102

37. Makita Z, Bucala R, Rayfield EJ, et al. (1994) Reactive glcosylation end-products in diabetic uremia. Lancet 343: 1519-1522

38. Gentil MA, Carriazzo A, Pavon MI, et al. (1991) Comparison of survival in continuous ambulatory peritoneal dialysis and hospital haemodialysis: a multicentric study. Nephrol Dial Transplant 6: 444-451

39. Maiorca R, Vonesh E, Cancarini GC, et al. (1991) A multicenter, selection-adjusted comparison of patient and technique survivals among CAPD and haemodialysis. Periton Dial Int 11: 118-127

40. Held PJ, Port FK, Turenne MN, Gaylin DS, Hamburger RJ, Wolfe RA (1994) Continuous ambulatory peritoneal dialysis and haemodialysis: a comparison of patient mortality with adjustment for comorbid conditions. Kidney Int 45 : 1163-1169

41. Bloembergen W, Port FK, Mauger EA, Wolfe RA (1995) A comparison of mortality between patients treated with haemodialysis and peritoneal dialysis. J Am Soc Nephrol 6: 177-183

42. Lowrie EG, Huang WH, Lew N (1995) Death risk predictors among peritoneal and haemodialysis patients: a preliminary comparison. Am J Kidney Dis 26: 220-228

43. Disney AP (1995) Demography and survival of patients receiving treatment for chronic renal failure in Australia and New Zealand: report on dialysis and renal transplantation treatment from the Australia and New Zealand Dialysis and Transplant Registry. Am J Kidney Dis 25: 165-175

44. Fenton S, Desmeules M, Copleston P, et al. (1995) Renal replacement therapy in Canada: a report from the Canadian Organ Replacement Registry. Am J Kidney Dis 25: 134-150 